\title{
STUDY OF POLYACRYLIC ACID ADSORPTION ON THE INTERFACE OF HYDROXYAPATITE - ELECTROLYTE SOLUTIONS
}

\author{
I.T. HAFEZ ${ }^{1}$ \\ C.A. PARASKEVA ${ }^{1,3, *}$ \\ P.G. KLEPETSANIS ${ }^{2,3}$ \\ P.G. KOUTSOUKOS ${ }^{1,3}$
}

Received: 06/05/10

Accepted: 08/09/10

\author{
${ }^{1}$ University of Patras, Department of Chemical Engineering \\ ${ }^{2}$ University of Patras, Department of Pharmacy \\ Rion, Patras, GR-26504, Greece \\ ${ }^{3}$ Institute of Chemical Engineering and High Temperature \\ ICE-HT/FORTH, Patras, 265 00, Greece
}

\section{ABSTRACT}

The adsorption of polyacrylic acid (PAA) on hydroxyapatite (HAP) from HAP saturated solutions was studied in this work as a function of PAA concentration, temperature, $\mathrm{pH}$ and ionic strength. In all experiments, the adsorption was studied under conditions of negatively charged adsorbent and adsorbate, respectively. These conditions ensured that adsorption was not electrostatically favored. The solution composition was found to influence significantly the maximum of the adsorbed amount. In fact, the adsorption of PAA, was found to increase with ionic strength, due to the decrease of double layer thickness of HAP particles. The effect of temperature and ionic strength on the kinetics of adsorption are also reported. Adsorption isotherms obtained at $30^{\circ} \mathrm{C}$ were found to be Langmuirtype, while at higher temperatures they were of the Brunauer-Emmett-Teller (BET) type. The absorbed amount of PAA was found to decrease with temperature, while it increased with ionic strength. For $\mathrm{pH}$ values lower than 6.5, the adsorption increased while for $\mathrm{pH}$ between 6.5 and 9 the adsorbed amount remained almost constant.

KEYWORDS: hydroxyapatite, polyacrylic acid, adsorption, temperature, ionic strength.

\section{INTRODUCTION}

Hard tissues of vertebrates (bones, dentin, dental enamel) are natural composite materials, which contain hydroxyapatite (HAP, $\left.\mathrm{Ca}_{5}\left(\mathrm{PO}_{4}\right)_{3} \mathrm{OH}\right)$ together with protein, water and other organic substances. HAP has received much attention as one of the prime candidates for a number of medical applications in orthopedics and dentistry, due to their thermodynamic stability (Koutsoukos and Nancollas, 1981) and biocompatibility (Ignjatovic et al., 1999; Bakos et al., 1999; Deng et al., 2001; Spanos et al., 2002). In addition, HAP as well as other calcium phosphate phases such as calcium phosphate dihydrate (DCPD, $\mathrm{CaHPO}_{4} .2 \mathrm{H}_{2} \mathrm{O}$ ) and octacalcium phosphate (OCP, $\mathrm{Ca}_{4} \mathrm{H}\left(\mathrm{PO}_{4}\right)_{3} .2 .5 \mathrm{H}_{2} \mathrm{O}$ ), have been reported to bind strongly silicate sand grains providing well consolidated sandpacks with resistance up to $70 \mathrm{~atm}$ (Paraskeva et al., 2000, Hafez et al., 2006). Similar work has been presented by the same group of authors, where calcium sulfate carbonate (Lioliou et al., 2006) and calcium carbonate (Lioliou et al., 2007) salts were used for the consolidation of unconsolidated or poorly consolidated materials. The motivation of this particular study was the development of an inexpensive and environmentally friendly method for the consolidation of soft or poorly consolidated sand layers in oilfields that suffer from sand production during oil production. The main idea behind the effort for the amelioration of the substrate consolidation was the in situ uniform precipitation of an environmentally friendly sparingly soluble salt (calcium phosphate) on the grain surfaces. The gradual growth of these crystals led to the formation of bridges between neighboring grains resulting to a consolidated sand layer.

In order to increase the mechanical strength of synthetic composites that contain HAP or to improve strength of sand layers consolidated by precipitation of calcium phosphate salts, polymers can be introduced to mimic the polymer-HAP composites encountered in hard tissues like teeth and bone of 
vertebrates. The role of macromolecules in the mineralization process of calcium phosphate phases has been a subject of many studies (Garcia-Ramos et al., 1982; Tsortos and Nancollas, 2002; Bradt et al., 1999). Adsorption capacity of HAP is prerequisite for biomineralization, because upon surgical implantation, HAP surfaces are covered rapidly by biomolecules present in the body fluids. Interactions between HAP and biomolecules such as BSA and lysozyme (Kandori et al., 1997; 2000) show that the adsorption isotherms are pseudo-Langmuir type and that they are dominated by electrostatic interactions between the charged molecules and the oppositely charged sites of the HAP surface. Barroug et al. (Barroug et al., 1997) showed that in succinylated lysozyme adsorption hydrophobic rather than electrostatic interactions were prevalent, a fact attributed to a different structure of modified lysozyme. Moreover, the non-electrostatic mechanism of the adsorption of enzyme catalase on HAP at conditions where adsorbent and adsorbate were both negatively charged has been reported (Barroug et al., 1998).

The adsorption of Poly Acrylic Acid (PAA) on HAP is well documented. The role of molecular weight as well as the molecular association of the PAA chains has been investigated (Misra, 1991; 1996). The experimentally obtained adsorption isotherms showed three important features: (i) they all showed a maximum (except for the PAA-sodium salt), (ii) Langmuir-type fit was obtained at lower concentrations, and (iii) they were all irreversible. The presence of an adsorption maximum was explained qualitatively on the basis of increasing self-association of the PAA chains with concentration and because of the lower ability of the associated molecules to adsorb due to their used up hydrogen-bonding capability. The effect of other important solution parameters such as. solution $\mathrm{pH}$, temperature etc which are important for the polymer structure in solution and for its concomitant adsorption of HAP, have not been adequately addressed. In the present work the adsorption and the kinetics of adsorption of PAA on well characterized synthetic HAP crystals in aqueous solutions, as a function of $\mathrm{pH}$, temperature and ionic strength was investigated.

\section{EXPERIMENTAL PART}

\section{Preparation of Hydroxyapatite crystals}

The preparation of HAP crystals was done by slow mixing of calcium chloride and potassium dihydrogen phosphate solutions $\left(25 \mathrm{mM}\right.$ and $15 \mathrm{mM}$ respectively) at $70^{\circ} \mathrm{C}$ and at $\mathrm{pH}=10$, maintained by the addition of standard $\mathrm{KOH}$ solution ( $1 \mathrm{~N}$, Titrisol, MERCK). $\mathrm{pH}$ measurements were done with a combined glass - $\mathrm{Ag} / \mathrm{AgCl}$ electrode connected to a $\mathrm{pH}$-meter (Metrohm, E691). The solution was kept homogeneous with magnetic stirring. The total volume $(2 \mathrm{~L})$ of the calcium and phosphate solutions was added over a period of 2 hours. Next, the precipitated crystals were aged for four days in the mother liquor at $40^{\circ} \mathrm{C}$, filtered, washed three times with triply distilled water and dried at $60^{\circ} \mathrm{C}$ overnight. The specific surface area (SSA) of the crystals was determined by multiple point nitrogen adsorption BET (Micromeritics, Gemini analyzer), and was equal to $61 \mathrm{~m}^{2} \mathrm{~g}^{-1}$. The aged crystalline solid was characterized by powder X-ray diffraction (Philips, PW 1830/40), scanning electron microscopy (JEOL, JSM5200) and by chemical analysis (determination of calcium/phosphate molar ratio). For the chemical analysis, a small, accurately weighed quantity of HAP crystals was dissolved in hydrochloric acid and was diluted to a final volume of $50 \mathrm{~mL}$ with triply distilled water. Calcium concentration was determined by atomic absorption spectrometry (PerkinElmer, AAnalyst 300), and phosphate spectrophotometrically by the vanado-molybdate complex method (SHIMADZU, UV-1601). Chemical analysis gave a molar calcium to phosphate ratio of $1.67 \pm 0.02$ (three replicates).

\section{Preparation of HAP saturated solutions}

$100 \mathrm{mg}$ of the HAP crystals were suspended in $1 \mathrm{~L}$ of sodium chloride solutions of ionic strength in the range between $0.1-0.5 \mathrm{~mol} \mathrm{dm}$. The suspension was magnetically stirred for 7 days, past which it was filtered through membrane filters (Millipore, $0.22 \mu \mathrm{m}$ ).

\section{Measurement of PAA concentration}

Polyacrylic acid $25 \%(\mathrm{w} / \mathrm{v}$ ) aqueous solution (Polysciences, Inc.) with an average molecular weight of 50,000 was used without any further purification. PAA stock solutions ranging between $50-1500$ $\mathrm{mg} \mathrm{l}^{-1}$ were prepared by dissolution in HAP-saturated solutions, at constant ionic strength. PAA concentration was measured from the absorbance at $210 \mathrm{~nm}$ (SHIMADZU, UV-1601). The calibration curve followed the linear Beer's law for PAA concentrations below 20 0ppm. Preliminary 
experiments showed that neither calcium nor phosphate ions cause significant interferences in the PAA determination.

\section{Adsorption measurements}

A small, accurately weighed amount of HAP crystals (ca. $50 \mathrm{mg}$ ) was suspended, in a series of PAA-HAP saturated solutions $\left(20 \mathrm{~mL}\right.$ each, solid to liquid ratio $=2.5 \mathrm{mg} \mathrm{ml}^{-1}$ ) in high density polyethylene vials placed in a thermostatted water bath. The $\mathrm{pH}$ value of each suspension was measured and was adjusted to the desirable values by the addition of small volumes of $\mathrm{NaOH}$ standard solution. Care was taken that ionic strength did not change significantly from the alkali addition. The adsorption experiments were done at 30,50 and $70^{\circ} \mathrm{C}$. The suspensions were agitated in the water bath and past an equilibration time of 24 hours, they were filtered through membrane filters (Millipore, $0.22 \mu \mathrm{m}$ ). The equilibrium concentration of PAA was measured in the filtrates. In each series of experiments blank solutions (without HAP) were included, to make sure that PAA was not adsorbed on the membrane filters and/or on the walls of the vials used for the equilibration of the solutions with the solid substrate. PAA adsorbed onto the HAP crystals (i.e., surface concentration of PAA, $\Gamma$ ) was determined by the difference between initial and final concentrations (expressed as $\mathrm{mg} \mathrm{m}^{-2}$ ),

$\Gamma=\frac{\left(\mathrm{C}_{\mathrm{i}}-\mathrm{C}_{\mathrm{f}}\right) * \mathrm{~V}}{\mathrm{~W} * \mathrm{SSA}}$

where $C_{i}$ and $C_{f}$ are the PAA concentrations in solution before and after adsorption $\left(\mathrm{mg} \mathrm{l}^{-1}\right), \mathrm{V}$ the volume of the suspension, W the mass of the HAP $(\mathrm{g})$ and SAA is the specific surface area $\left(\mathrm{m}^{2} \mathrm{~g}^{-1}\right)$ of the HAP crystals used as the sorbent. All adsorption experiments were done in duplicate, and the data presented are average values.

\section{RESULTS AND DISCUSSION}

HAP - Interaction with PAA.

In Figure 1, the X-ray diffraction patterns of pure HAP crystals (1a), HAP crystals after adsorption of PAA (initial concentration of $100 \mathrm{mg} \mathrm{L}^{-1}$ ) (1b) and HAP crystals following adsorption of PAA (initial concentration of $\left.1200 \mathrm{mg} \mathrm{L}^{-1}\right)$ are presented. It can be seen that the X-ray diffraction pattern of all materials (curves 1a-c) correlate well with the reference pattern (JCPDS, 1996). However, the intensities of the reflections corresponding to the (002), (102) and (210) planes decreased in curves $1 \mathrm{~b}, \mathrm{c}$, suggesting that the PAA interaction with the respective planes resulted in the reduction of the crystallinity. The intensity of all the other characteristic reflections of HAP was not affected by the presence of PAA.

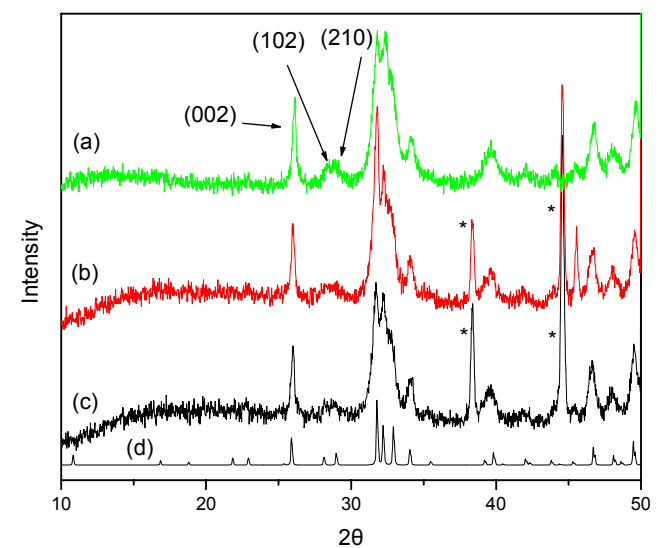

Figure 1. X-ray diffraction pattern of (a) HAP synthetic crystals, (b) HAP after adsorption PAA, initial concentration $100 \mathrm{mg} \mathrm{L}^{-1}$, (c) HAP past PAA adsorption, (d) HAP spectrum from JCPDS database (Card No. 9-432), initial concentration $1200 \mathrm{mg} \mathrm{L}^{-1}$

$\left(\mathrm{pH}=7.0\right.$, ionic strength $\left.=0.5 \mathrm{~mol} \mathrm{dm}^{-3} \mathrm{NaCl}, 70^{\circ} \mathrm{C}\right)$

(asterisks correspond to sample holder)

\section{Effect of $p H$}

In Figure 2, the dependence of adsorption of PAA on HAP crystal surface at different $\mathrm{pH}$ values, at temperatures $\left(30\right.$ and $50^{\circ} \mathrm{C}$ ) and ionic strength $0.1 \mathrm{M} \mathrm{NaCl}$ is shown. In these experiments, the initial PAA concentration was equal to $280 \mathrm{mg} \mathrm{L}^{-1}$. In all cases (temperature, ionic strength), the adsorption 
isotherms were found to follow the same pattern. The adsorption of PAA onto HAP increased upon increasing $\mathrm{pH}$. A plateau value of the adsorbed PAA was reached in the $\mathrm{pH}$ range between $6.5-9$. Taking into account the given pKa values (De Stefano et al.,2000) at the same experimental conditions (ionic strength, temperature) and assuming that the presence of calcium ions do not interfere much with the given pKa values (comparison of the work of De Stefano and Porasso et al. (1999)), using the Henderson-Hasselbalch equation we calculated that at $\mathrm{pH}=4.5$ PAA has a degree of dissociation about 0.15 whereas at $6.5<\mathrm{pH}<9$ a degree of dissociation between 0.94 and 0.99 , i.e. almost completely dissociated. In the dissociated state, PAA chains are more available for interaction with HAP surfaces either electrostatically or through the formation of hydrogen bonds with the surface groups contributing to the development of the surface charge $\left(\mathrm{OH}\right.$ and $\left.\mathrm{PO}_{4}\right)$.

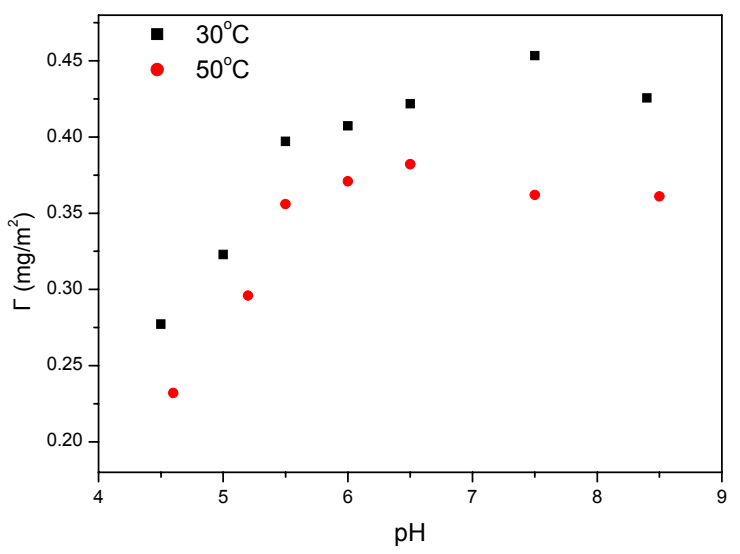

Figure 2. Variation of the surface concentration, $\Gamma$, of PAA with $\mathrm{pH}$ at $30^{\circ} \mathrm{C}(\cdot)$ and $50^{\circ} \mathrm{C}(\bullet)$ for the adsorption of PAA on HAP crystals $\left(\mathrm{PAA}_{\text {initial }}=280 \mathrm{mg} \mathrm{L}^{-1}\right.$ and I $\left.=0.1 \mathrm{~mol} \mathrm{dm}^{-3}\right)$

\section{Kinetics of Adsorption}

Adsorption kinetics of PAA on HAP was investigated at 30,50 and $70^{\circ} \mathrm{C}$ at $\mathrm{pH}=7$ and ionic strength values 0.1 and $0.5 \mathrm{~mol} \mathrm{dm}^{-3}$ adjusted with $\mathrm{NaCl}$. The initial concentration of PAA was $250 \mathrm{mg} \mathrm{I}^{-1}$. The results of the PAA uptake as a function of time are shown in Figures 3 and 4 . The adsorption-time profiles for both ionic strength values investigated suggested a first-order process, consistent with equation 2:

$-\frac{d C}{d t}=k C$

where $\mathrm{C}$ is the adsorbate concentration in solution, and $\mathrm{k}$ the apparent adsorption rate constant. Integration of equation (2) yielded:

$C=C_{o} \exp (-k t)$

In equation (3) $\mathrm{C}_{0}$ is the initial PAA concentration in solution. The adsorption density is thus:

$q_{t}=q_{e}[1-\exp (-k t)]$

where $q_{t}$ and $q_{e}$ stands are the adsorption density at a given time and at equilibrium, respectively. The values of the apparent rate constants calculated according to Eq. (4), for the experimental conditions of the present work are summarized in Table 1.

Table 1. Apparent adsorption rate constants at different values of temperature and ionic strength

\begin{tabular}{ccccc}
\hline & $\begin{array}{c}\text { Ionic strength } \mathrm{NaCl} \\
(\mathrm{M})\end{array}$ & $30^{\circ} \mathrm{C}$ & $50^{\circ} \mathrm{C}$ & $70^{\circ} \mathrm{C}$ \\
\hline$k$ & 0.1 & 0.226 & 0.237 & 0.252 \\
$\left(\mathrm{~min}^{-1}\right)$ & 0.5 & 0.161 & 0.176 & 0.193 \\
\hline
\end{tabular}




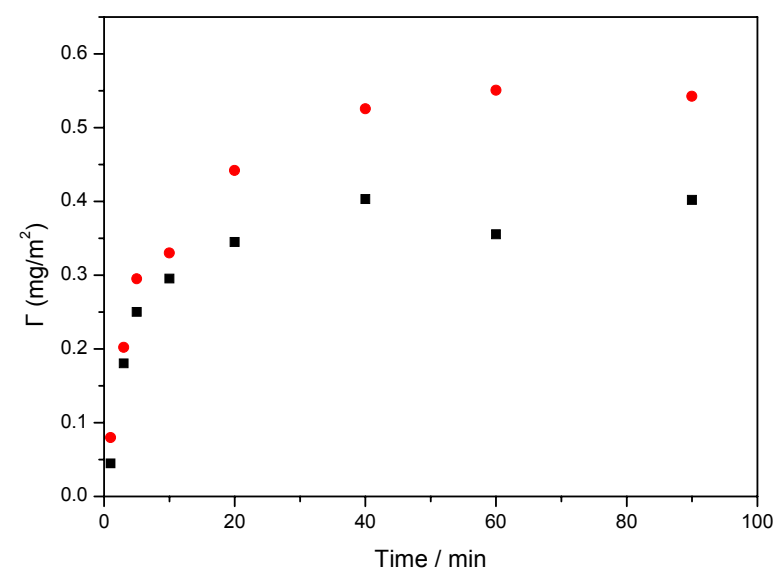

Figure 3. Variation of the surface concentration, $\Gamma$, of $P A A$ with incubation time at $30^{\circ} \mathrm{C}$ for the adsorption of PAA on HAP crystals at $0.1 \mathrm{~mol}^{-\mathrm{dm}^{-3}}(-)$ and $0.5 \mathrm{~mol} \mathrm{dm}^{-3}(\bullet)$. Initial concentration of $\mathrm{PAA}=300 \mathrm{mg} \mathrm{L}^{-1}$ and $\mathrm{pH}=7.0$

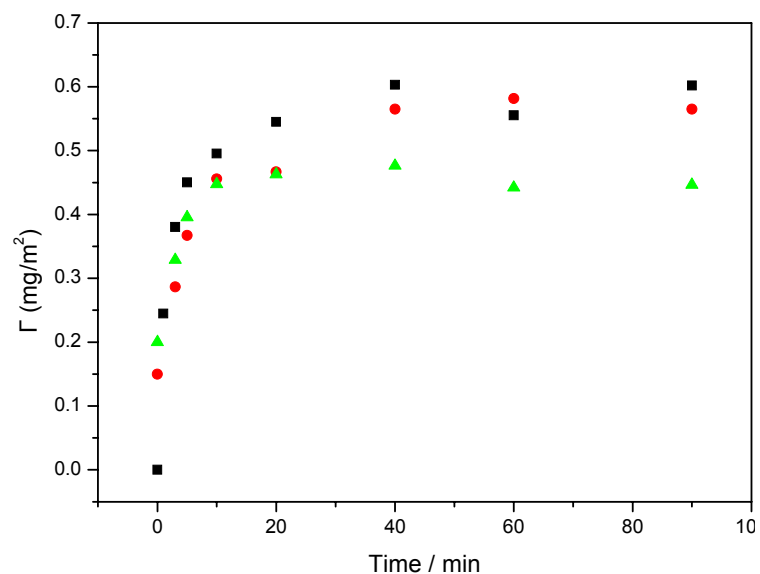

Figure 4. Variation of the surface concentration, $\Gamma$, of PAA with incubation time at $30^{\circ} \mathrm{C}(\cdot), 50^{\circ} \mathrm{C}(\bullet)$ and $70^{\circ} \mathrm{C}(\triangle)$ for the adsorption of PAA on

HAP crystals. Initial concentration of PAA $=300$ $\mathrm{mg} \mathrm{L}^{-1}, \mathrm{I}=0.5 \mathrm{~mol} \mathrm{dm}^{-3}$ and $\mathrm{pH}=7.0$

According to the Arrhenius formalism for the temperature dependence of the apparent rate constants for adsorption:

$k=\operatorname{Aexp}\left(-\Delta \mathrm{H}^{\circ}\right.$ ads $\left./ \mathrm{RT}\right)$

where $\Delta H^{\circ}$ ads is the apparent heat energy for the adsorption of PAA on HAP, A the pre-exponential factor, $\mathrm{R}$ the gas constant and $\mathrm{T}$ the absolute temperature. From logarithmic plots of Ink as a function of $1 / \mathrm{T}$ (Figure 5) the apparent heat energy was calculated equal to $2.11 \mathrm{KJ}^{\text {mole }}{ }^{-1}$ and 3.83 $\mathrm{KJ} \mathrm{mole}^{-1}$ for 0.1 .and $0.5 \mathrm{~mol} \mathrm{dm}^{-3}$ respectively. The adsorption was very fast and equilibrium was obtained within 40 min as may be seen from the kinetics plots shown in Figures 3 and 4 .

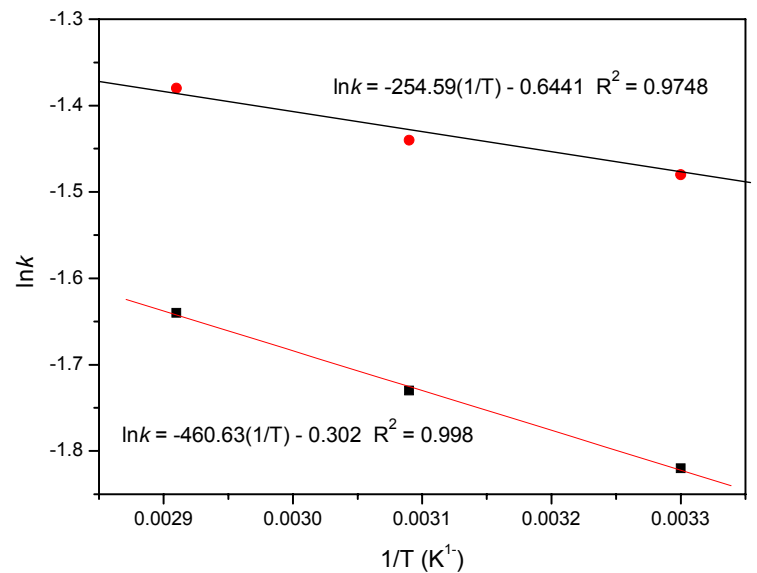

Figure 5. Arrhenius type plot for the adsorption of PAA on HAP crystals at ionic strength $0.1 \mathrm{~mol} \mathrm{dm}^{-3}(\cdot)$ and $0.5 \mathrm{~mol} \mathrm{dm}^{-3}(\bullet)$ at $\mathrm{pH}=7.0$.

\section{Effect of ionic strength and temperature}

The adsorption isotherms of PAA adsorption on HAP crystals, at different temperature and ionic strength values are shown in Figures $6 \mathrm{a}, 6 \mathrm{~b}$ and 7 . All adsorption isotherms where measured at $\mathrm{pH}$ $=7.0$. At $30^{\circ} \mathrm{C}$ (Figure $6 \mathrm{a}$ ) the isotherms were found to follow the Langmuir formalism, while at higher temperatures $\left(50\right.$ and $\left.70^{\circ} \mathrm{C}\right)$ the $\mathrm{BET}$ isotherm yielded better fit for the experimental data (Figures $6 \mathrm{~b}$ and 7 ). The Langmuir isotherm used to fit the adsorption data of PAA onto HAP, is given by equation (6):

$\frac{x}{m}=\frac{k_{1} k_{2} C_{e q}}{1+k_{1} C_{e q}}$

Upon rearrangement, Equation (7) is obtained: 


$$
\frac{C_{e q}}{x / m}=\frac{1}{k_{1} k_{2}}+\frac{C_{e q}}{k_{2}}
$$

where $C_{e q}$ is the equilibrium concentration of the adsorbate (PAA), $x$ the amount of adsorbate bound to the adsorbent (HAP) and $m$ the amount of adsorbent. Constant $k_{1}$, is defined as the adsorption coefficient or affinity constant and is related the magnitude of the forces involved in the binding process. The Langmuir - capacity constant, $k_{2}$, is a measure of the apparent maximum amount of adsorbate that may be adsorbed per unit weight of adsorbent. The adsorption isotherm at $50^{\circ} \mathrm{C}$ (Figure $6 \mathrm{~b}$ ) showed, for both values of ionic strength examined, a Langmuir-type pattern, up to $\mathrm{C}_{\text {eq }}$ values of $800 \mathrm{mg} \mathrm{I}^{-1}$, with a plateau corresponding to an adsorption density of about $0.4 \mathrm{mg} \mathrm{m}^{-2}$ and about $0.65 \mathrm{mg} \mathrm{m}^{-2}$ for ionic strength $0.1 \mathrm{~mol} \mathrm{dm}^{-3} \mathrm{NaCl}$ and $0.5 \mathrm{~mol} \mathrm{dm}^{-3} \mathrm{NaCl}$, respectively.
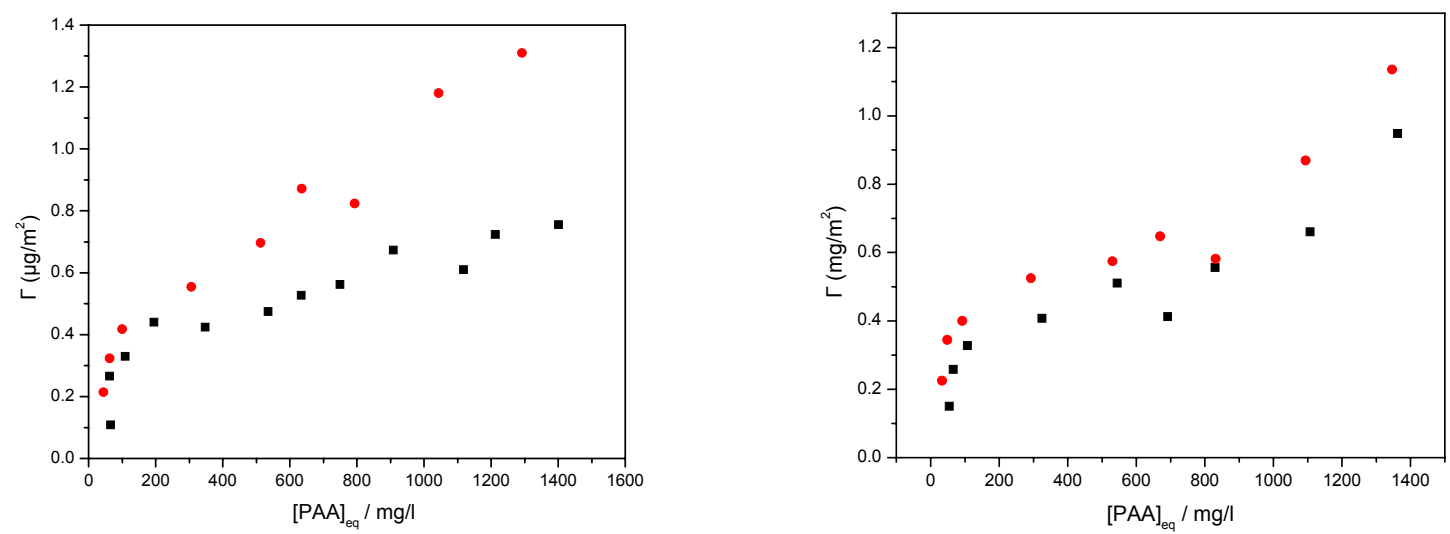

Figure 6. Variation of the surface concentration, $\Gamma$, of PAA as a function of the equilibrium PAA concentration in the solution, [PAA] $]_{\text {eq }}$, for the adsorption of PAA on HAP crystals

(b) at IS $=0.1 \mathrm{~mol} \mathrm{dm}^{-3}(\cdot)$ and $0.5 \mathrm{~mol} \mathrm{dm}^{-3}(\bullet), \mathrm{pH}=7.0$.

a) $\mathrm{T}=30^{\circ} \mathrm{C}$ and b) $\mathrm{T}=50^{\circ} \mathrm{C}$

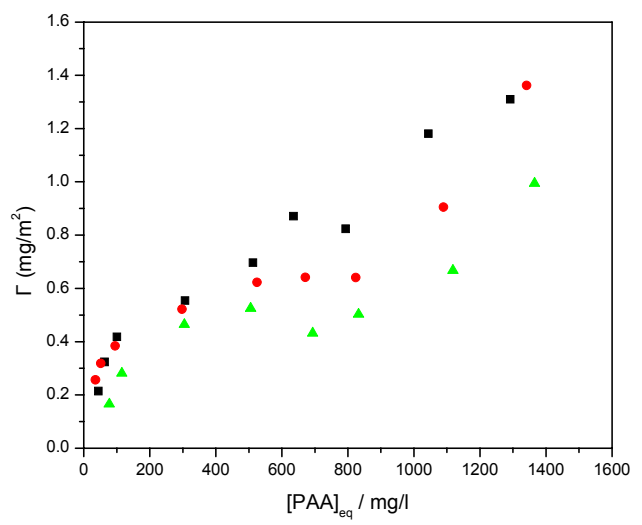

Figure 7. Variation of the surface concentration, $\Gamma$, of PAA as a function of the equilibrium PAA concentration in the solution, [PAA] $]_{\mathrm{eq}}$, for the adsorption of PAA on HAP crystals at $30^{\circ} \mathrm{C}(\cdot), 50^{\circ} \mathrm{C}(\bullet)$ and $70^{\circ} \mathrm{C}(\triangle) . \mathrm{I}=0.5 \mathrm{~mol} \mathrm{dm} \mathrm{m}^{-3}$ and $\mathrm{pH}=7.0$.

These plateau values were extended over an equilibrium concentration range between $300-800 \mathrm{mg} \mathrm{L}^{-1}$. Next, adsorption density increased further up to $1500 \mathrm{mg} \mathrm{L}^{-1}$. Past the $800 \mathrm{mg} \mathrm{L}^{-1}$ there was no plateau value. Figure 7 shows the isotherms obtained at $70^{\circ} \mathrm{C}$ (curve $6 \mathrm{c}$ ), exhibited the same trend as at $50^{\circ} \mathrm{C}$, reaching a plateau value at equilibrium concentration $500 \mathrm{mg} \mathrm{L}^{-1}$ and adsorption density of about $0.5 \mathrm{mg} \mathrm{m}^{-2}$ and about $0.3 \mathrm{mg} \mathrm{m}^{-2}$ for ionic strength of $0.1 \mathrm{~mol} \mathrm{dm}^{-3}$ and $0.5 \mathrm{~mol} \mathrm{dm}^{-3}$ respectively. The adsorption data obtained for the temperature and ionic strength values investigated were fitted to Langmuir-type isotherm, as can be seen in the Figure 8 . The results obtained are summarized in Table 2. 
Table 2. Apparent affinity constants and maximum surface concentration of PAA obtained from Langmuir plots

\begin{tabular}{ccccc}
\hline Temperature & \multicolumn{2}{c}{$\boldsymbol{k}_{\mathbf{1}}\left(\mathbf{L} \mathbf{~ g}^{-\mathbf{1}}\right)$} & \multicolumn{2}{c}{$\boldsymbol{k}_{\mathbf{2}}\left(\mathbf{m g ~ g}^{-\mathbf{1}}\right)$} \\
\cline { 2 - 5 }$\left({ }^{\circ} \mathbf{C}\right)$ & $\mathbf{0 . 1 M}$ & $\mathbf{0 . 5 M}$ & $\mathbf{0 . 1 M}$ & $\mathbf{0 . 5 M}$ \\
\hline 30 & 3.37 & 2.71 & 51.57 & 90.09 \\
\hline 50 & 6.88 & 5.38 & 42.62 & 40.98 \\
\hline 70 & 9.72 & 8.02 & 28.22 & 34.71 \\
\hline
\end{tabular}

In all cases, the increase of ionic strength resulted to higher adsorption, as can be seen in Figures $6 \mathrm{a} \& 6 \mathrm{~b}$. At high ionic strength values the inter-chain repulsion of the polymer is screened and the polyelectrolyte behaves more like an uncharged polymer. It adopts conformations with loops and tails, and the adsorbed amount increases. The addition of sodium chloride facilitates the adsorption process, by two simultaneous effects: (a) the added salt reduces the intra-inter-electrostatic repulsive interactions of the polyelectrolyte chains. The compensation of $\mathrm{Na}^{+}$ions around the negatively charged carboxyl groups of the PAA chains causes significant changes to the conformation of the molecules. The chains adopt a coiled conformation through intrer-intramolecular bonding and thus occupy less space on the surface of the substrate as well on the bulk solution, (Meszaros et al., 2002) and (b) the salt screens the repulsion (salt effect) of equal charges between polyelectrolyte chains and HAP surface. Considering the conditions of adsorption (negatively charged polymer-negative surface of HAP), specific non-electrostatic interactions between the HAP surface and PAA molecules may be postulated (van de Steeg et al., 1992).

At both ionic strength values, increase in temperature resulted in the decrease of adsorption as may be seen in Figure 9, because temperature affects the conformation of the polyelectrolyte chains which now occupy more space on HAP surfaces at higher temperature values. For ionic strength $0.1 \mathrm{~mol} \mathrm{dm}^{-3}$ and at temperatures 30 and $50^{\circ} \mathrm{C}$ the temperature increase, did not affect significantly the adsorption density. Increase of the solution temperature resulted in the decrease of the charge screening effect, increasing the activation energy for the adsorption of PAA on HAP. In this case, the repulsion of the polyelectrolyte chains from the negatively charged HAP surface is intensified. Due to the fact that PAA adsorption includes hydrogen bonding, it is anticipated that the adsorption is reduced due hydrogen bonds breakage (Page et al., 1993).

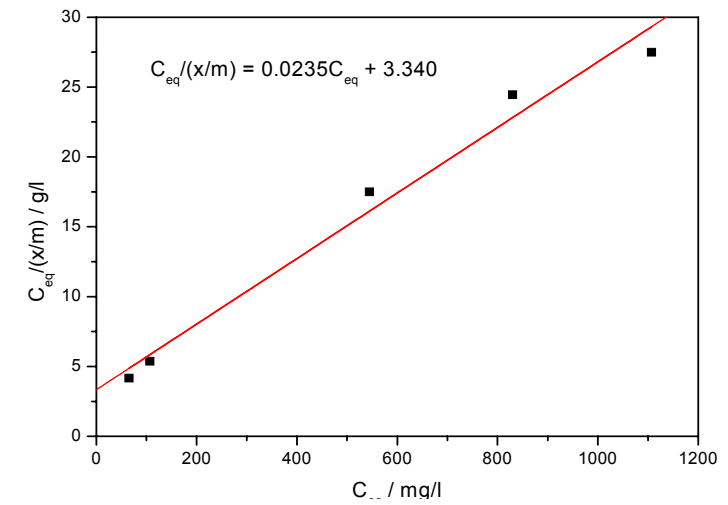

Figure 8. Plot of eq. 6 for the adsorption of PAA on HAP crystals at $\mathrm{pH}=7.0$, $\left(\mathrm{T}=50^{\circ} \mathrm{C}, \mathrm{IS}=0.1 \mathrm{~mol} \mathrm{dm}^{-3}\right)$.

The solid line corresponds to the Langmuir model

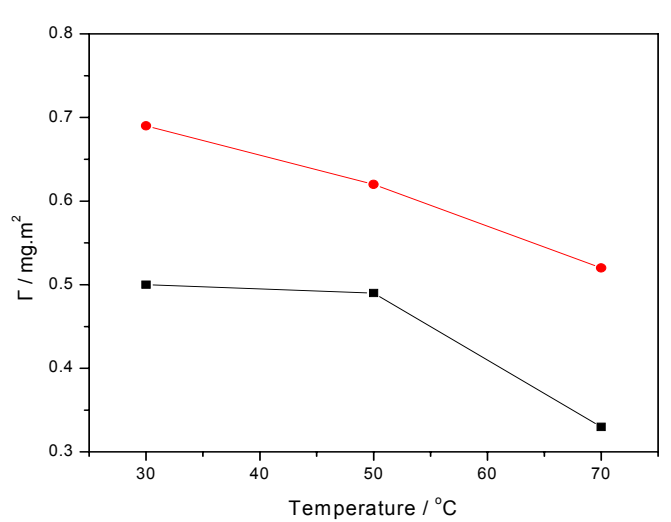

Figure 9. Variation of the surface concentration, $\Gamma$, of PAA with temperature for the adsorption of PAA on HAP crystals at ionic strength $0.1 \mathrm{~mol} . \mathrm{dm}^{-3}(\cdot)$ and 0.5 $\mathrm{mol} \cdot \mathrm{dm}^{-3}(\bullet)$. Initial PAA concentration $=$

$$
500 \mathrm{mg}^{-1} \mathrm{I}^{-1}, \mathrm{pH}=7.0
$$

\section{Calculation of thermodynamic parameters of adsorption}

The standard free energy of adsorption ( $\Delta \mathrm{G}^{\circ}$ ads $)$ can be calculated using equation (8):

$\Delta \mathrm{G}^{\mathrm{o}}{ }_{\mathrm{ads}}=-\mathrm{RTIn} k_{1}$ 
The enthalpy change $\left(\Delta \mathrm{H}^{\circ}\right.$ ads $)$ and entropy change $\left(\Delta \mathrm{S}^{\circ}\right.$ ads $)$ for adsorption were assumed to be temperature independent allowing for the enthalpy to be estimated from the temperature dependence of $\Delta \mathrm{G}^{\circ}$ ads, according to equation (9):

$\Delta \mathrm{G}^{\circ}{ }_{\text {ads }}=\Delta \mathrm{H}^{\circ}{ }_{\text {ads }}-\mathrm{T} \Delta \mathrm{S}^{\circ}{ }_{\text {ads }}$

The temperature dependence of $\Delta \mathrm{G}^{\circ}$ ads is shown in Table 3. The calculated apparent heat of adsorption was found $2.11 \mathrm{KJ} \mathrm{mol}^{-1}$ and $3.83 \mathrm{KJ} \mathrm{mol}^{-1}$ for ionic strength values 0.1 and $0.5 \mathrm{~mol} \mathrm{dm}^{-3}$, respectively. The low values of the heat of adsorption, suggested that the predominant interaction of PAA molecules with HAP surface is physical adsorption including hydrogen bonds, Van der Waals forces and bipolar interactions.

Table 3. Thermodynamic parameters for PAA molecules adsorption, on the surface of HAP crystals, at different temperatures and ionic strengths

\begin{tabular}{ccccccc}
\hline & \multicolumn{2}{c}{$30^{\circ} \mathrm{C}$} & \multicolumn{2}{c}{$50^{\circ} \mathrm{C}$} & \multicolumn{2}{c}{$70^{\circ} \mathrm{C}$} \\
\cline { 2 - 7 } & $0.1 \mathrm{M}$ & $0.5 \mathrm{M}$ & $0.1 \mathrm{M}$ & $0.5 \mathrm{M}$ & $0.1 \mathrm{M}$ & $0.5 \mathrm{M}$ \\
\hline $\begin{array}{c}\Delta \mathrm{G}^{\circ} \text { ads } \\
\left(\mathrm{KJ} \mathrm{mole}^{-1}\right)\end{array}$ & -3.06 & -2.51 & -5.18 & -4.52 & -6.48 & -5.94 \\
\hline $\begin{array}{c}\Delta \mathrm{H}^{\circ}{ }_{\text {ads }} \\
\left(\mathrm{KJ} \mathrm{mole}^{-1}\right)\end{array}$ & 2.11 & 3.83 & 2.11 & 3.83 & 2.11 & 3.83 \\
\hline $\begin{array}{c}-\mathrm{T} \Delta \mathrm{S}^{\circ}{ }^{\mathrm{ads}} \\
\left(\mathrm{KJ} \mathrm{mole}^{-1}\right)\end{array}$ & -5.17 & -6.34 & -7.29 & -8.35 & -8.59 & -9.77 \\
\hline
\end{tabular}

\section{CONCLUSIONS}

The adsorption of PAA from solutions onto HAP was investigated at controlled conditions. Both the kinetics of adsorption and the effect of variables, such as temperature, ionic strength and $\mathrm{pH}$, were investigated. The adsorption data at $30^{\circ} \mathrm{C}$ and at two ionic strength values $\left(0.1\right.$ and $\left.0.5 \mathrm{~mol} \mathrm{dm}^{-3}\right)$ gave excellent fit to a Langmuir-type isotherm. The adsorbed amount as a function of the equilibrium PAA concentration did not exhibit plateau following the Langmuir formalism. At 50 and $70^{\circ} \mathrm{C}$ and ionic strength values 0.1 and $0.5 \mathrm{~mol} \mathrm{dm}^{-3}$, the data gave excellent fit to BET-type (multilayer coverage) isotherms. A plateau value corresponding to an equilibrium concentration of $800 \mathrm{mg} \mathrm{L}^{-1}$ PAA was exhibited. The adsorption data for 50 and $70^{\circ} \mathrm{C}$ and up to the plateau of the respective isotherm were fitted to a Langmuir type model in order to evaluate the affinity constants and the maximum amount of PAA adsorbed, according to the respective model. Increase of the ionic strength resulted in an increase of the adsorption density because of: (a) the salt effect between HAP surface and PAA chains and (b) the reduction in electrostatic repulsion between the PAA chains. Change of the solution $\mathrm{pH}$ caused differences in the adsorption density of the PAA. The proton dissociation of the PAA chains increased with increase of the solution $\mathrm{pH}$, thus favoring the formation of hydrogen bonds between PAA and the HAP surface. Increase in temperature resulted in the decrease of PAA adsorption on HAP because of the higher efficiency of the screening effect and the decrease of hydrogen bond stability between PAA molecules in solution and HAP crystals.

\section{DEDICATION}

The present work is dedicated to our advisor Professor Alkis Payatakes who passed away in November 2009. We had the good fortune to have been his students or colleague. We have derived great benefits from Alkis and we express our gratitude.

\section{REFERENCES}

Bakos D., Soldan M. and Hernantez-Fuentes I. (1999), Hydroxyapatite-collagen-hyaluronic acid composite, Biomaterials, 20, 191-195.

Barroug A., Fastrez J., Lamaitre J. and Rouxhet P. (1997), Adsorption of Succinylated Lysozyme on Hydroxyapatite, Journal of Colloid and Interface Science, 189, 37-42.

Barroug A., Etienne L., Lamaitre J. and Rouxhet P. G. (1998), Adsorption of Catalase on Hydroxyapatite, Journal of Colloid and Interface Science, 208, 147-152.

Bradt J., Mertig M., Teresiak A. and Pompe W. (1999), Biomimetic Mineralization of Collagen by Combined Fibril Assembly and Calcium Phosphate Formation, Chemistry of Materials, 11, 26942701.

Deng X., Hao J. and Wang C. (2001), Preparation and mechanical properties of nanocomposites of poly(D,L-lactide) with Ca-deficient hydroxyapatite nanocrystals, Biomaterials, 22, 2867-2873. 
De Stefano C., Gianguzza A., Piazzese D. and Sammartano S. (2000), Polyacrylate Protonation in Various Aqueous Ionic Media at Different Temperatures and Ionic Strengths, Journal of Chemical and Engineering Data, 45, 876-881.

Garcia-Ramos J. V. and Carmona P. (1982), The effect of some homopolymers on the crystallization of calcium phosphates, Journal of Crystal Growth, 57, 336-342.

Hafez, I.T., Paraskeva, C.A. Toliza, A., Klepetsanis, P.G., Koutsoukos, P.G., Gustavsen, Ø., Østvold, T. and Payatakes, A.C. (2006), "Calcium Phosphate overgrowth on silicate sand grains", Crystal Growth and Design, 6 (3), 675-683, 2006

Ignjatovic N., Tomic S., Dakic M., Miljikovic M., Plasvic M. and Uskolovic D. (1999), Synthesis and properties of hydroxyapatite/poly-L-lactide composite biomaterials, Biomaterials, 20, 809-816.

JCPDS (1996) International Centre for Diffraction Data, 1996.

Kandori K., Horigami N., Kobayashi H., Yasukawa A. and Ishikawa T. (1997), Adsorption of Lysozyme onto Various Synthetic Hydroxyapatites, Journal of Colloid and Interface Science, 191, 498-502.

Kandori K., Mukai M., Yasukawa A. and Ishikawa T. (2000), Competitive and Cooperative Adsorptions of Bovine Serum Albumin and Lysozyme to Synthetic Calcium Hydroxyapatites, Langmuir, 16, 2301 2305.

Koutsoukos P. G. and Nancollas G. H. (1981), Crystal growth of calcium phosphates - Epitaxial considerations, Journal of Crystal Growth, 53, 10-19.

Lioliou, M. G., Paraskeva, C.A., Koutsoukos, P.G., Payatakes, A.C., (2006), 'Calcium sulfate precipitation in the presence of water-soluble polymers', Journal of Colloid and Interface Science, 303, 164-170.

Lioliou, M. G., Paraskeva, C.A., Koutsoukos, P.G., Payatakes, A.C, (2007), 'Heterogeneous Nucleation and Growth of Calcium Carbonate on Calcite and Quartz' Journal of Colloid and Interface Science, 308 (2), 421-428, 2007

Meszaros, R., Thompson, L., Bos, M., de Groot, P., (2002), Adsorption and electrokinetic properties of polyethylenimine on silica surfaces, Langmuir, 18, 6164.]

Misra D. N. (1991), Adsorption of Low Molecular Weight Poly(acrylic acid) on Hydroxyapatite: Role of Molecular Association and Apatite Dissolution, Langmuir, 7, 2422-2424.

Misra D. N. (1996), Adsorption of Polyacrylic Acids and Their Sodium Salts on Hydroxyapatite: Effect of Relative Molar Mass, Journal of Colloid and Interface Science, 181, 289-296.

Page M., Lecourtier J. and Noik C. (1993). Adsorption of Polyacrylamides and of Polysaccharides on Siliceous Materials and Kaolinite: Influence of Temperature, Journal of Colloid and Interface Science, 161, 450-454.

Paraskeva C. A., Charalampous P. C., Stokka L. E., Klepetsanis P. G., Koutsoukos P. G., Read P., Ostvold, T. and Payatakes A. C. (2000), Sandbed Consolidation with Mineral Precipitation, Journal of Colloid and Interface Science, 232, 326-339.

Porasso R., Benegas J., Van Ve Hoop M.A.G.T, Chemical and electrostatic association of various metal ions by poly(acrylic acid) and poly(methacrylic acid) as studied by potentiometry, J. Phys. Chem B (1999), 103, 2361-2365,

Spanos N., Deimede V. and Koutsoukos P. G. (2002), Functionalization of synthetic polymers for potential use as biomaterials: selective growth of hydroxyapatite on sulphonated polysulphone, Biomaterials, 23, 947-953.

Tsortos A. and Nancollas G. H. (2002), The Role of Polycarboxylic Acids in Calcium Phosphate Mineralization, Journal of Colloid and Interface Science, 250, 159-167.

van de Steeg H.G.M., Cohen Stuart M.A., de Keizer A. and Bijsterbosch B.H. (1992), Polyelectrolyte Adsorption: A Subtle Balance of Forces, Langmuir, 8, 2538-2546. 